Communication

\title{
Compact Antenna in 3D Configuration for Rectenna Wireless Power Transmission Applications
}

\author{
Alassane Sidibe ${ }^{1,2, *(\mathbb{D})}$, Alexandru Takacs ${ }^{1}$, Gaël Loubet ${ }^{1}$ (D) and Daniela Dragomirescu $^{1}$ (D) \\ 1 Laboratoire d'Analyse et d'Architecture des Systèmes du Centre National de la Recherche Scientifique \\ (LAAS-CNRS), Université de Toulouse, Centre National de la Recherche Scientifique (CNRS), Institut \\ National des Sciences Appliqués de Toulouse (INSA), Université Paul Sabatier, Toulouse III (UPS), \\ 31400 Toulouse, France; alexandru.takacs@laas.fr (A.T.); gael.loubet@laas.fr (G.L.); \\ daniela.dragomirescu@laas.fr (D.D.) \\ 2 Uwinloc, 9 Rue Humbert Tomatis, 31200 Toulouse, France \\ * Correspondence: alassane.sidibe@laas.fr
}

Citation: Sidibe, A.; Takacs, A.;

Loubet, G.; Dragomirescu, D.

Compact Antenna in 3D

Configuration for Rectenna Wireless

Power Transmission Applications.

Sensors 2021, 21, 3193. https://

doi.org/10.3390/s21093193

Academic Editor: Razvan D. Tamas

Received: 12 February 2021

Accepted: 28 April 2021

Published: 4 May 2021

Publisher's Note: MDPI stays neutral with regard to jurisdictional claims in published maps and institutional affiliations.

Copyright: (C) 2021 by the authors. Licensee MDPI, Basel, Switzerland. This article is an open access article distributed under the terms and conditions of the Creative Commons Attribution (CC BY) license (https:// creativecommons.org/licenses/by/ $4.0 /)$.

\begin{abstract}
This work presents methods for miniaturizing and characterizing a modified dipole antenna dedicated to the implementation of wireless power transmission systems. The antenna size should respect the planar dimensions of $60 \mathrm{~mm} \times 30 \mathrm{~mm}$ to be integrated with small IoT devices such as a Bluetooth Lower Energy Sensing Node. The provided design is based on a folded short-circuited dipole antenna, also named a T-match antenna. Faced with the difficulty of reducing the physical dimensions of the antenna, we propose a $3 \mathrm{D}$ configuration by adding vertical metallic arms on the edges of the antenna. The adopted 3D design has an overall size of $56 \mathrm{~mm} \times 32 \mathrm{~mm} \times 10 \mathrm{~mm}$ at $868 \mathrm{MHz}$. Three antenna-feeding techniques were evaluated to characterize this antenna. They consist of soldering a U.FL connector on the input port; vertically connecting a tapered balun to the antenna; and integrating a microstrip transition to the layer of the antenna. The experimental results of the selected feeding techniques show good agreements and the antenna has a maximum gain of $+1.54 \mathrm{dBi}$ in the elevation plane (E-plane). In addition, a final modification was operated to the designed antenna to have a more compact structure with a size of $40 \mathrm{~mm} \times 30 \mathrm{~mm} \times 10 \mathrm{~mm}$ at $868 \mathrm{MHz}$. Such modification reduces the radiation surface of the antenna and so the antenna gain and bandwidth. This antenna can achieve a maximum gain of $+1.1 \mathrm{dBi}$ in the E-plane. The two antennas proposed in this paper were then associated with a rectifier to perform energy harvesting for powering Bluetooth Low Energy wireless sensors. The measured RF-DC (radiofrequency to direct current) conversion efficiency is $73.88 \%$ (first design) and $60.21 \%$ (second design) with an illuminating power density of $3.1 \mu \mathrm{W} / \mathrm{cm}^{2}$ at $868 \mathrm{MHz}$ with a $10 \mathrm{k} \Omega$ load resistor.
\end{abstract}

Keywords: compact antenna; wireless power transmission (WPT); energy harvesting; rectenna; wireless sensors

\section{Introduction}

Over the last decades, we have been faced with the miniaturization of electronic devices, especially in the field of wireless systems. The aim is to have multiple functionalities on an ever-smaller surface area. Recent IoT applications (Internet of Things) tend to employ tiny and low power electronic components [1]. However, batteries are still widely used for powering the devices despite their significant size and the frequent need for replacement. An alternative is using a battery-free system powered by energy harvesting $(\mathrm{EH})$ or wireless power transmission (WPT), for instance, based on a rectenna circuit.

A rectenna is a combination of a rectifier and an antenna used to scavenge ambient or specially generated far-field radiofrequency (RF) waves [2]. The implementation of a rectenna in a battery-free system can allow increasing its lifetime, reducing its manufacturing costs, while ensuring reliable performances for decades. Several kinds of application 
exist, such as, for instance, rectennas, which were developed for a biomedical device pasted on the human body [3] or used in the IoT domain [4-6].

The antenna is a ubiquitous element in IoT and other wireless applications. However, the required size stays important due to the important dependence of the geometrical elements with the targeted wavelength. Several miniaturization techniques are described in the literature. Structural modification on a Printed Circuit Board (PCB) antenna consists of acting on the geometry of the antenna or by adding another element on the antenna shape.

In this sense, a coupling element, such as a rectangular ring, can allow a reduction in size and an increase in bandwidth as presented in [7]. Traditionally, small size antennas are designed by using meander lines which reduce the resonant frequency [8]. Fractal geometry is also used to miniaturize antennas [9]. Another possibility is to add reactive loading elements. This technique is employed in [10] through an LC load (a combination of a lumped inductor and a distributed capacitor). Miniaturization can also be achieved by reducing the guided wavelength through the use of a higher permittivity material, such as a ceramic - polymer composite [11]. Recent research activities were focused on developing small antennas on metamaterial as presented in [12]. In this paper, we present a miniaturization technique which consists of shaping the antenna to form a three-dimensional (3D) structure tuned for the Industrial Scientific and Medical (ISM) $868 \mathrm{MHz}$ frequency band. This configuration allows us to have an electrically small antenna as described in Section 2. A more compact antenna based on the previous one is designed to compare the trade-off between size and rectenna performances. Then, Section 3 presents the experimental results of the fabricated antennas with different feeding methods to validate the use of the U.FL connector for the next steps. Simulations were carried out on the Ansys HFSS software and verified with far-field measurements performed in an anechoic chamber. The final section of this paper describes an original concept of powering a Bluetooth Low Energy Sensing Node embedded in concrete element with a compact and efficient rectenna design.

\section{Design of a Compact 3D Dipole Antenna}

\subsection{Antenna Miniaturization Methods and the First Design of the Compact 3D Dipole}

In this study, we proposed a miniaturized antenna design for WPT applications. An antenna is a resonant structure with a proper frequency depending on its length. Therefore, there are size and performance limitations for small antennas [13,14]. The size reduction imposes a smaller radiation resistance, so a lower radiation efficiency and a bandwidth limitation. Wheeler defines a electrically small antenna as one defined by the formula given in Equation (1). It means that the antenna sphere is smaller than the radian sphere, also defined as Wheeler Cap. $\lambda$ is the wavelength at the operating frequency, $k$ represents the free-space wavenumber and a is the minimum antenna sphere radius. The choice of proposing an electrically small antenna should allow us to have an antenna design in the maximum planar size of $60 \mathrm{~mm} \times 30 \mathrm{~mm}$. Nevertheless, the antenna bandwidth reduction does not matter with the applications in the ISM $868 \mathrm{MHz}$ frequency band. The targeted antenna gain is about $+1 \mathrm{dBi}$ less compared to a conventional dipole antenna gain $(+2.15 \mathrm{dBi})$.

$$
k \cdot a<1 \text { with } k=\frac{2 \pi}{\lambda}
$$

The proposed design is based on a dipole antenna according to its multiple advantages, such as the symmetry of its shape and radiation pattern, its easy and low-cost fabrication, and the possibility of receiving balanced signals. The required dimensions of $60 \mathrm{~mm} \times 30 \mathrm{~mm}$ allow us to have a conventional half-wavelength dipole antenna at $2 \mathrm{GHz}$, as presented in Figure 1.

Starting from this antenna at $2 \mathrm{GHz}$, we had investigated a technique for reducing the physical dimensions of the antenna without significantly degrading its performances ( $+1 \mathrm{dBi}$ less of the gain). The planar structure of the final antenna design on an FR4 substrate is presented in Figure 2. Overall, a folded dipole antenna designed after size optimization 
(Antenna in Figure 3 stamped "None") presents a resonant frequency close to $1.12 \mathrm{GHz}$ regarding the return loss (S11) equal to $-5.2 \mathrm{~dB}$.
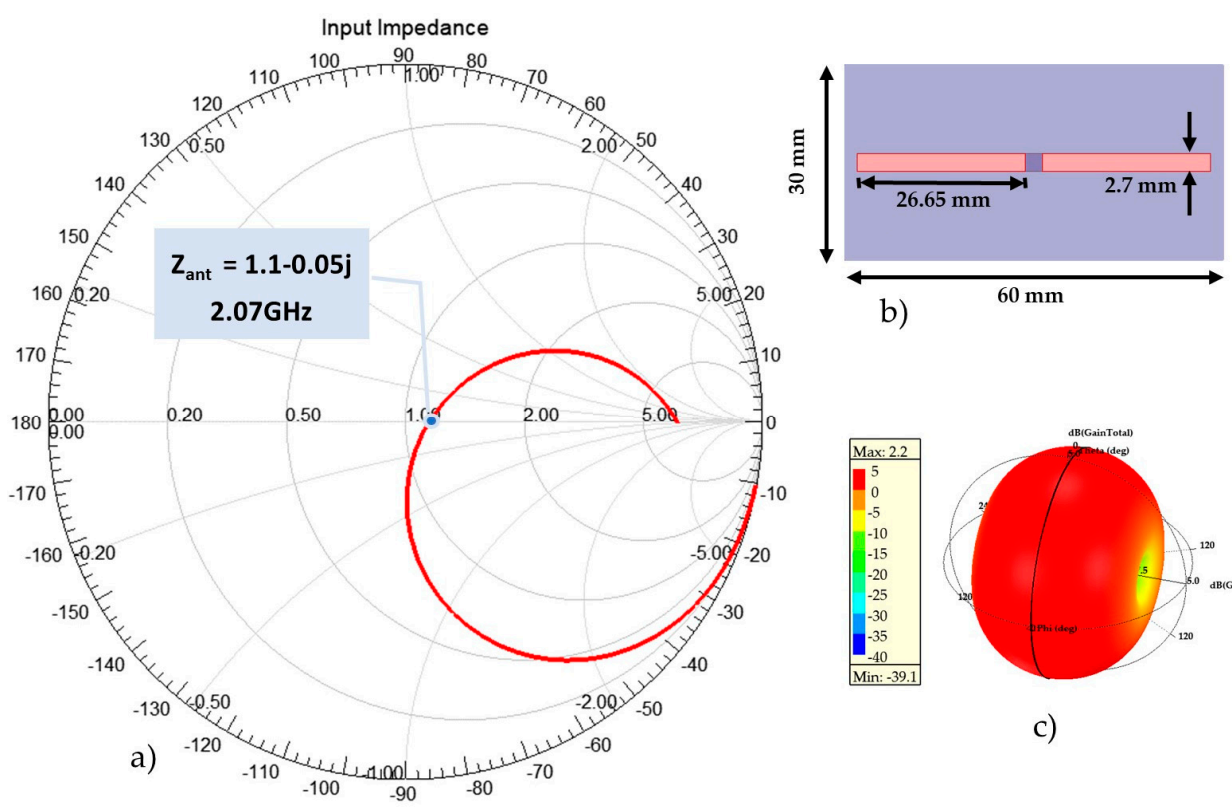

b)

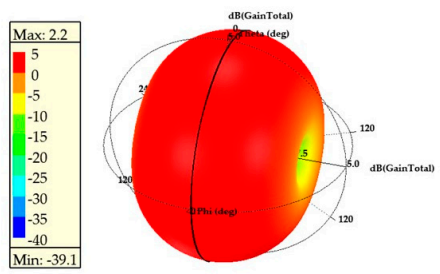

c)

Figure 1. Conventional dipole antenna simulated on the required size dimensions. (a) The input impedance representation on Smith chart; (b) Half-wavelength antenna dimensions; (c) Simulated $3 \mathrm{D}$ radiation pattern at $2 \mathrm{GHz}$.

This antenna can be considered as a half-wavelength dipole antenna at $1.12 \mathrm{GHz}$. The total length of each folded arm $\left(\mathrm{L}_{1}+\mathrm{W}_{1}+\mathrm{L}_{2}=43.4 \mathrm{~mm}\right)$ is closed to the quarter wavelength $\left(<0.25 \cdot \lambda_{\mathrm{g}}=31.9 \mathrm{~mm}\right)$. Figure 3 presents the width tuning of the inductive shorting loop to make a T-match structure [15]. The resonance frequency is greatly influenced by the width and the length of the T-match structure. As seen in Figure 3, the absence of the T-match structure (None) shows a significant resonant frequency of the antenna higher than $1.12 \mathrm{GHz}$ where the impedance is $(17.35+\mathrm{j} \cdot 27.3) \Omega$. The shorting line $(\mathrm{W}=0)$ connected to the two dipole arms downshifts the resonant frequency around $1.07 \mathrm{GHz}$. Thereafter, the geometric parameters ( $\mathrm{W}$ and $\mathrm{L}$ ) were adjusted to match the input impedance of the antenna $(50 \Omega)$ at lower frequency.
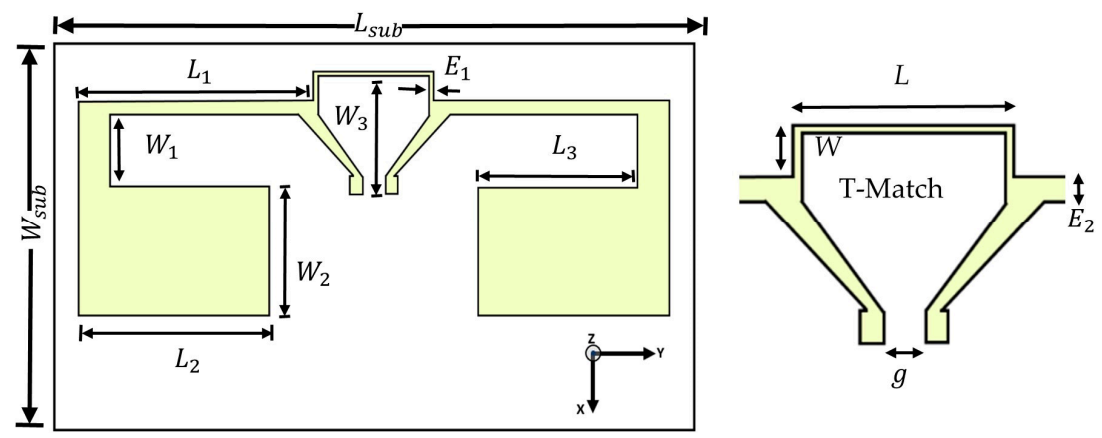

Figure 2. Detailed geometry of the compact, T-match dipole antenna on an FR4 substrate $\left(L_{\text {sub }}=56 \mathrm{~mm}, W_{\text {sub }}=32 \mathrm{~mm}, L_{1}=20.65 \mathrm{~mm}, W_{1}=5.95 \mathrm{~mm}, L_{2}=16.8 \mathrm{~mm}, W_{2}=10.5 \mathrm{~mm}, L_{3}=14 \mathrm{~mm}\right.$, $W_{3}=9.625 \mathrm{~mm}, E_{1}=0.35 \mathrm{~mm}, E_{2}=1.05 \mathrm{~mm}, \mathrm{~g}=2.03 \mathrm{~mm}$ ). 

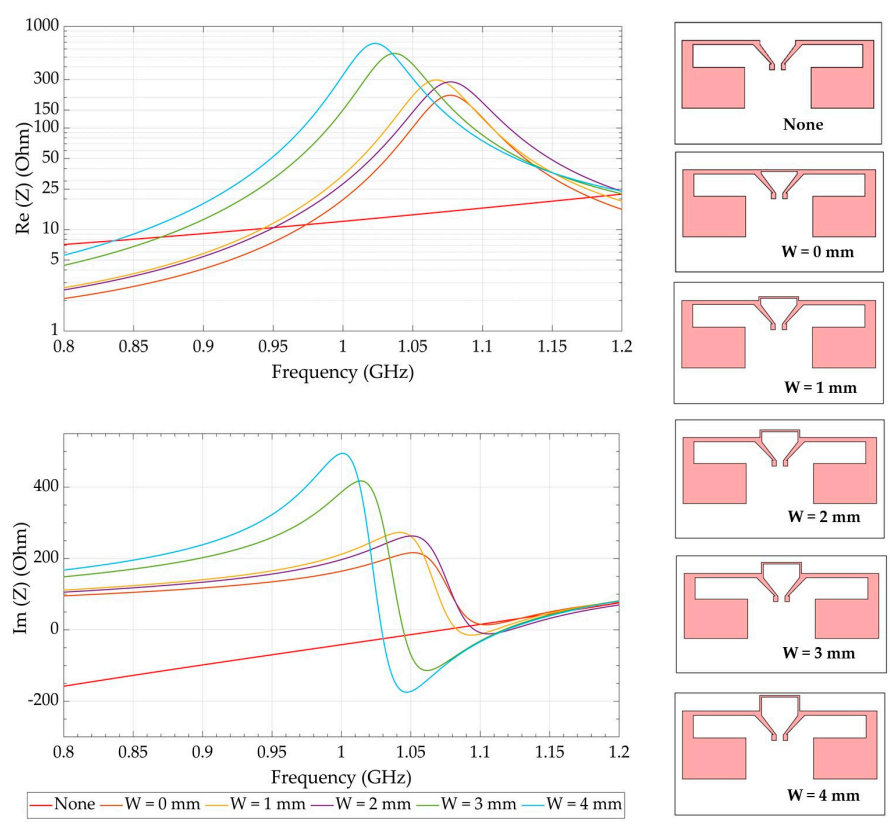

Figure 3. Evolution of the input impedance (Real and Imaginary parts) as function of the frequency with various shorting line width $(\mathrm{W})$ values.

The simulated results of the optimization on HFSS software are displayed in Figures 3 and 4 . The return loss (reflection coefficient $S_{11}$ ) indicates how much the power is reflected on the input port when the antenna is excited. A practical criterion for the antenna (impedance) input matching is generally specified at $-10 \mathrm{dBm}$ at least for a reference impedance of $50 \Omega$. As represented in Figure 4, the greater the length $(\mathrm{L})$ of the short-circuited line, the more the antenna resonates at higher frequency.

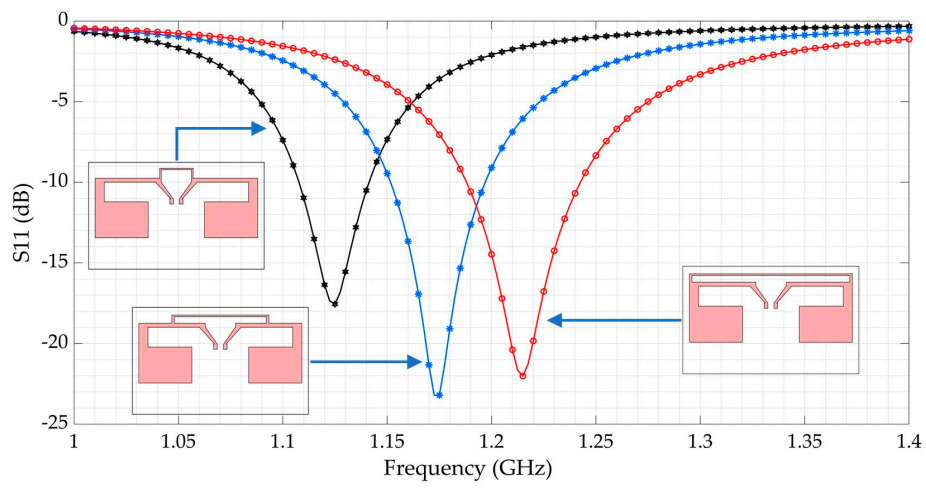

Figure 4. Simulated S11 (return loss) of the antenna for different configurations; $\mathrm{L}=10 \mathrm{~mm}$ (black), $\mathrm{L}=30 \mathrm{~mm}$ (blue) and $\mathrm{L}=51.4 \mathrm{~mm}$ (red).

For the next miniaturization step, the T-match structure parameters were fixed to those which give the lower resonant frequency ( $\mathrm{W}=4 \mathrm{~mm}$ and $\mathrm{L}=10 \mathrm{~mm}$ ). To downshift the operating frequency obtained from the planar antenna from $1.12 \mathrm{GHz}$ to $868 \mathrm{MHz}$, a $3 \mathrm{D}$ configuration was investigated. The operating/resonant frequency of the antenna can be downshifted by connecting two metal strands [16]. In our case, two capacitive metallic arms with a height of $10 \mathrm{~mm}$ are vertically connected to the planar antenna with a short transmission line (Figure 5a). This line's position at the edge of the planar antenna was tuned to obtain an operating frequency as close as possible to $868 \mathrm{MHz}$ with a bandwidth of $30.7 \mathrm{MHz}$. 


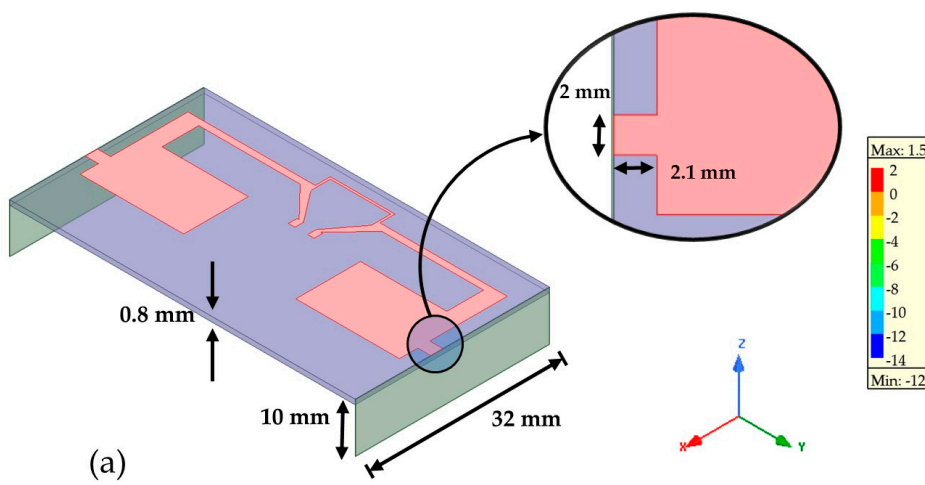

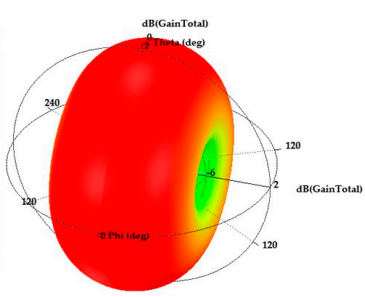

(b)

Figure 5. (a) Geometry of the 3D configuration antenna with the connected metallic arms; (b) Simulated 3D gain polar plot at $868 \mathrm{MHz}$.

In our application at the European ISM $868 \mathrm{MHz}$ frequency band, a narrow band antenna is not critical. The radiation pattern looks like a doughnut shape and the maximum simulated gain is $+1.5 \mathrm{dBi}$ (Figure $5 \mathrm{~b}$ ).

\subsection{Second Miniaturized Antenna Design}

In terms of compactness, the previous antenna was modified and two different antennas (A1 and A2) were designed, respectively, the unconnected and connected antenna to the metallic arms. The horizontal arms of the planar dipole are folded in a spline shape to occupy the blue part display in Figure 6a and reduce the length $\left(L_{s u b}\right)$ of the planar antenna. By the way, the width of the arms was adjusted to the substrate width. This curving shape was obtained after several optimized simulations, and the size of A2 (represented in Figure $6 \mathrm{~b}$ ) is only $40 \mathrm{~mm} \times 30 \mathrm{~mm} \times 10 \mathrm{~mm}$.
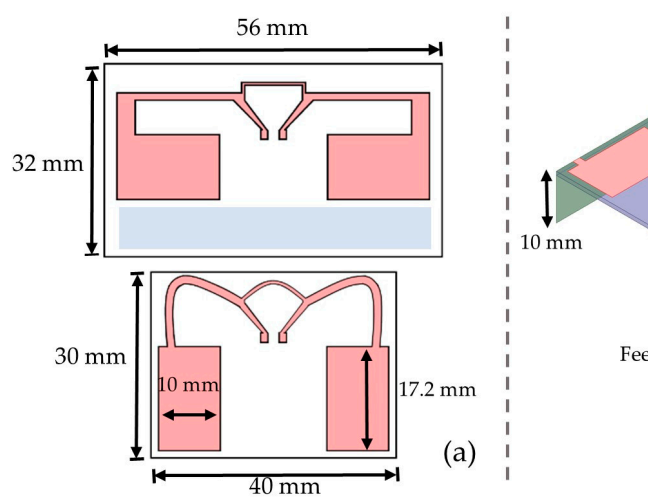
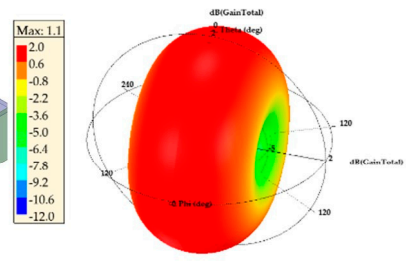

(b)

Figure 6. Designed antennas on HFSS: (a) The first miniaturized antenna and the second miniaturized antenna named A2: 3D FDA; (b) 3D polar plot of the radiation pattern of A2 antenna at the resonant frequency (HFSS results).

The simulations performed show an operating frequency at $1.15 \mathrm{GHz}$ for A1 and $868 \mathrm{MHz}$ for A2. However, there is a small gain reduction of $0.4 \mathrm{dBi}$ compared to the previous designed antenna, so that we still respect the first condition of a maximum $+1 \mathrm{dBi}$ loss on the gain from a conventional dipole antenna. The radiation patterns in the E-plane and the H-plane are presented in Figure 7. 


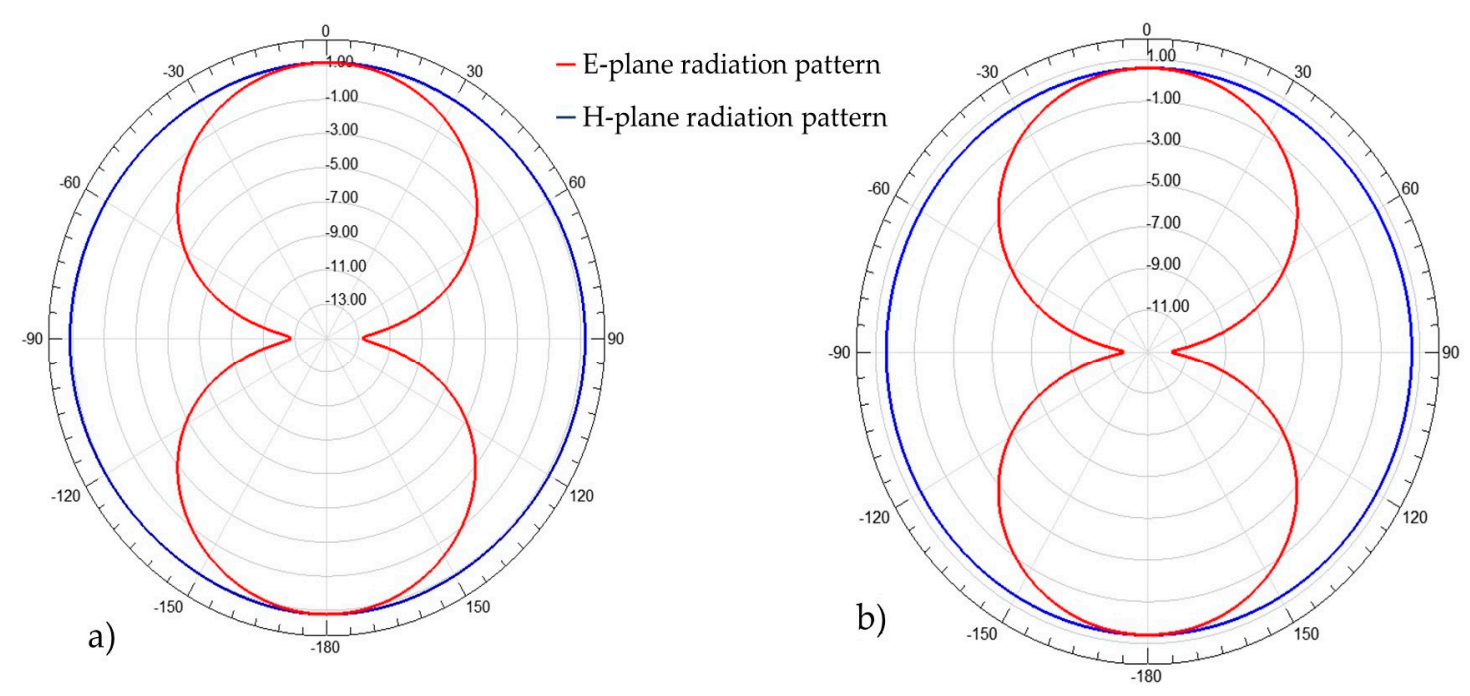

Figure 7. Radiation pattern on the E-plane and H-plane at $868 \mathrm{MHz}$. (a) The antenna first 3D dipole antenna in Section 2.1; (b) The modified 3D dipole antenna (A2).

\section{Characterization of the Designed Antennas}

The designed antenna was manufactured in an FR4 substrate with a thickness of $0.8 \mathrm{~mm}$. Dipole antennas require a balanced-unbalanced (balun) circuit or a microstrip transition for a coaxial measurement. The balun allows canceling the flowing current on the outside surface of the outer coaxial conductor and then affects the measurement [17]. In the literature, several dipole antenna-feeding techniques were proposed. A microstrip tapered balun was used as a feeding line in [18] and a microstrip-to-coplanar (CPW) feed network balun for a flexible bowtie antenna in [19]. On the other hand, in many electronic devices especially in IoT, a surface mount coaxial U.FL connector is strongly used for characterization and RF connection for embedded antennas. Its advantages are its low cost, small size and light weight.

To well characterize our designed antenna, three feeding methods were selected. The first feeding technique carried in this paper is to use a U.FL connector [20]. The pads of the connector were soldered on the antenna feeding pads, as seen in Figure 8a. The second method consists of vertically connecting a designed tapered microstrip balun (Figure $8 b$ ). The last one is a microstrip transition: while one pad of the antenna is connected to a $50 \Omega$ transmission line, the other balanced pad is connected to the ground plane (Figure 8c). For the return loss $\left(\mathrm{S}_{11}\right)$ and the gain measurements, a compatible coaxial cable was connected to the vector network analyzer (VNA). The measured return loss is plotted in Figure 9 (by using three different connection methods). They all fit well to each other but present a $15 \mathrm{MHz}$ frequency shift compared to the simulation. The same frequency shift can be observed in Figure 10 between simulation and measurement for the curved 3D antenna A2. Without the two connected arms, the simulated and measured return loss fit perfectly, but once they are connected, a $50 \mathrm{MHz}$ frequency shift appears. The difference is mainly due to the soldering effect and the vertical capacitive arms whose dimensions are not perfectly respected as compared with the simulated ones. The A2 antenna was measured with a U.FL connector and resonates at $878 \mathrm{MHz}$, as shown in Figure 10. The measured and simulated gain in the E-plane are shown in Figure 11. 
(a)

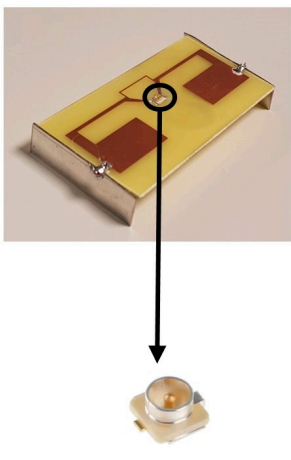

(b)

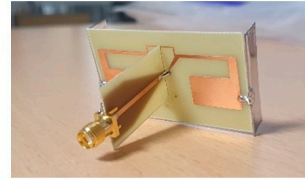

Microstrip feed

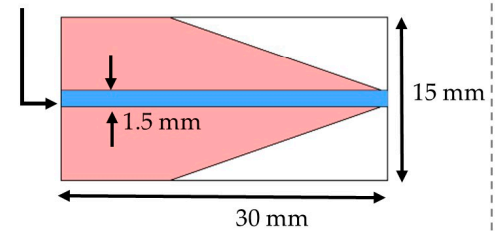

Top layer

Bottom layer (Ground Plane) (c)
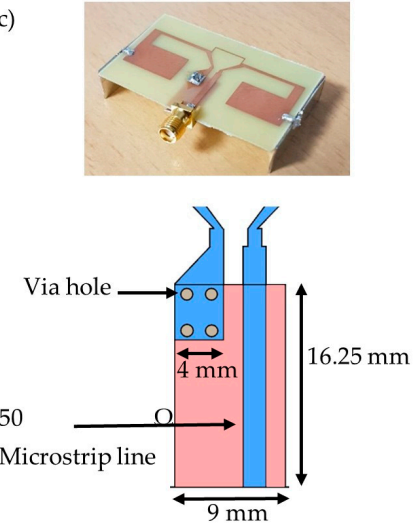

Figure 8. (a) Antenna with a U.FL connector named AC; (b) Antenna with connected tapered balun named ATB; (c) Antenna with integrated microstrip transition named AIT.

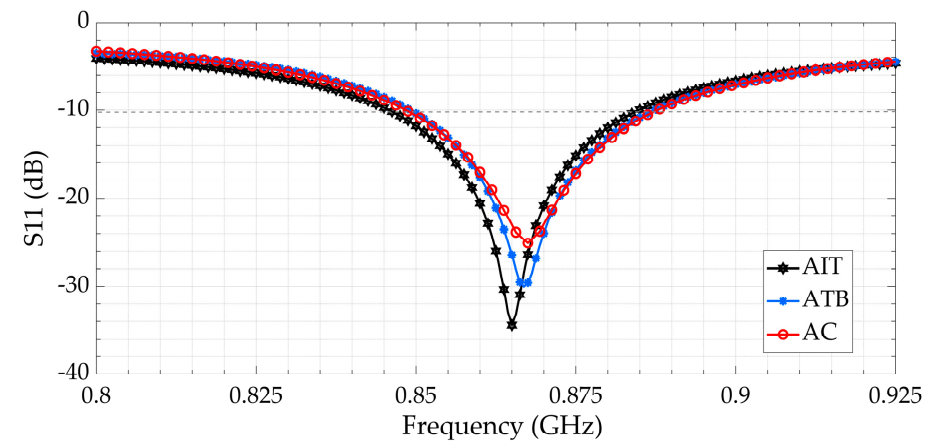

Figure 9. Comparison of the measured return loss (S11) of the D1 antenna with different feeding methods.

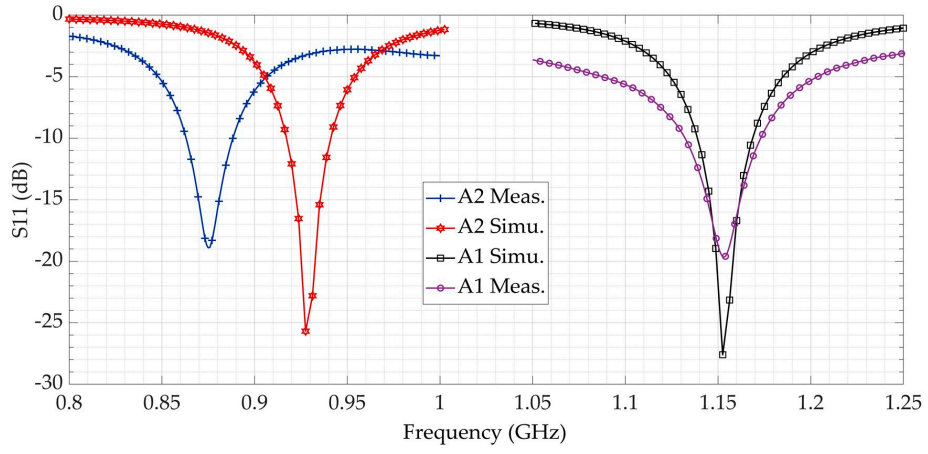

Figure 10. Measured and simulated reflection coefficient of the A1 and A2 antennas. 


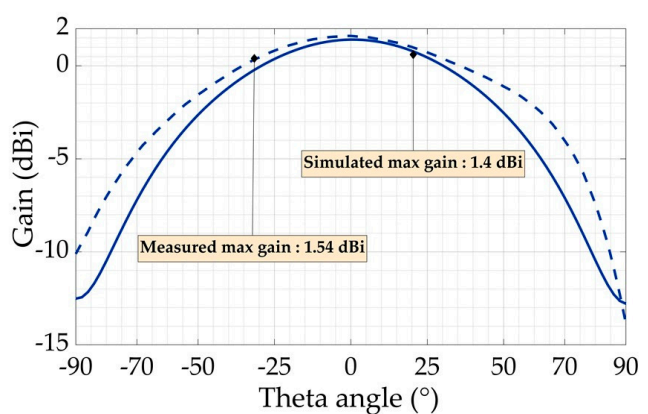

(a)

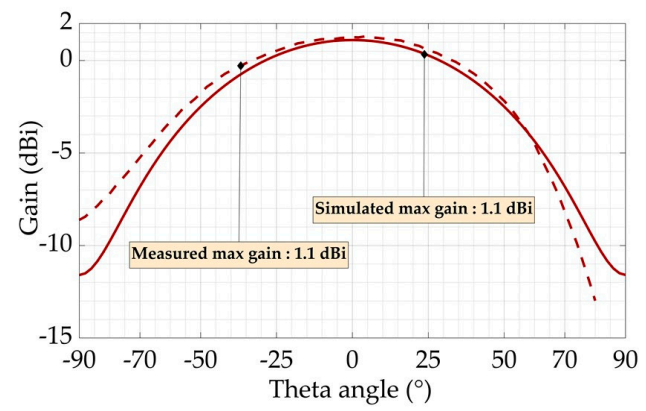

(b)

Figure 11. Simulated (dashed line) and measured (continuous line) radiation pattern (gain plot in the E-plane): (a) AC antenna; (b) A2 antenna at the resonant frequency (868 MHz).

Table 1 compares in terms of performances and size some state-of-the-art antennas and the presented solution operating in ISM $868 \mathrm{MHz}$ or ISM $915 \mathrm{MHz}$ frequency bands. The proposed compact 3D antenna was implemented on an FR4 substrate that is lossier as compared with the substrates used by other state-of-the-art designs.

Table 1. Comparison with the different compact antennas for rectenna of IoT devices in the state of the art.

\begin{tabular}{|c|c|c|c|c|c|c|}
\hline Ref. & Freq. (MHz) & Type & Max Gain (dBi) & BW (MHz) & Substrate & Size $(\mathrm{mm} \times \mathrm{mm} \times \mathrm{mm})$ \\
\hline [21] & 878 & Dual Band PIFA & $+1.8-+1.9$ & $80(855-937)$ & Duroid 5880 & $80 \times 45\left(0.03 \cdot \lambda^{2}\right)$ \\
\hline [22] & 868 & UCA PIFA & +0.71 & $23(857-880)$ & FR4 & $34 \times 80\left(0.02 \cdot \lambda^{2}\right)$ \\
\hline [16] & 915 & Slot loaded DB folded dipole & +1.87 & Not available & Arlon $25 \mathrm{~N}$ & $60 \times 60 \times 60\left(0.006 \cdot \lambda^{3}\right)$ \\
\hline [23] & 868 & 3D single arm bowtie & +0.19 & 90 & Ultralam & $50 \times 50 \times 10\left(0.0006 \cdot \lambda^{3}\right)$ \\
\hline \multirow{2}{*}{ This work } & \multirow{2}{*}{868} & \multirow{2}{*}{ 3D modified T-match dipole } & +1.54 & $32(865-897)$ & \multirow{2}{*}{ FR4 } & $56 \times 32 \times 10\left(0.0004 \cdot \lambda^{3}\right)$ \\
\hline & & & +1.1 & $26(862-888)$ & & $40 \times 30 \times 10\left(0.0003 \cdot \lambda^{3}\right)$ \\
\hline
\end{tabular}

BW: Bandwidth, PIFA: Planar Inverted F-Antenna, DB: Dual Band.

\section{Rectenna and Wireless Power Transmission Experimentations}

The antennas presented in this paper are more compact than the 3D antennas in [16,23], and exhibit the best tradeoff between size, gain and bandwidth and can be good candidates for WPT applications. They were integrated in rectennas used for battery-free wireless sensors embedded in concrete structures [24,25].

The rectifier part is designed using ADS/Momentum software from Keysight. The circuit is designed on a microstrip coupled transmission line allowing differential feeding by the dipole antenna (Figure 12). It is composed of a SMS7630-005LF Schottky diode, an LC matching network (L1-C1) ensuring $50 \Omega$ input impedance at the input of the rectifier and a low pass filter formed by a shunt capacitor (C3) and a resistive load (R1). However, considering the nonlinear behavior of the Schottky diode, the rectifier was designed and optimized for a low input power of $-15 \mathrm{dBm}$ and a $10 \mathrm{k} \Omega$ resistor to emulate the load (that is the input impedance of the power management unit (PMU)). The simulation result was performed and described in [24]. Two rectennas, R1 and R2, in Figure 12 represent the rectifier with the antenna $\mathrm{AC}$ without any connector and $\mathrm{A} 2$, respectively. They were made by integrating the rectifier with the antennas on the same substrate. Their characterization was performed in an anechoic chamber at the distance of $1.5 \mathrm{~m}$ from the patch-transmitting antenna, and the harvested DC power was measured across a $10 \mathrm{k} \Omega$ load through a multimeter. The rectennas R1 and R2 allow a harvested DC voltage of $788 \mathrm{mV}$ and $726 \mathrm{mV}$ for $1 \mu W / \mathrm{cm}^{2}$. 


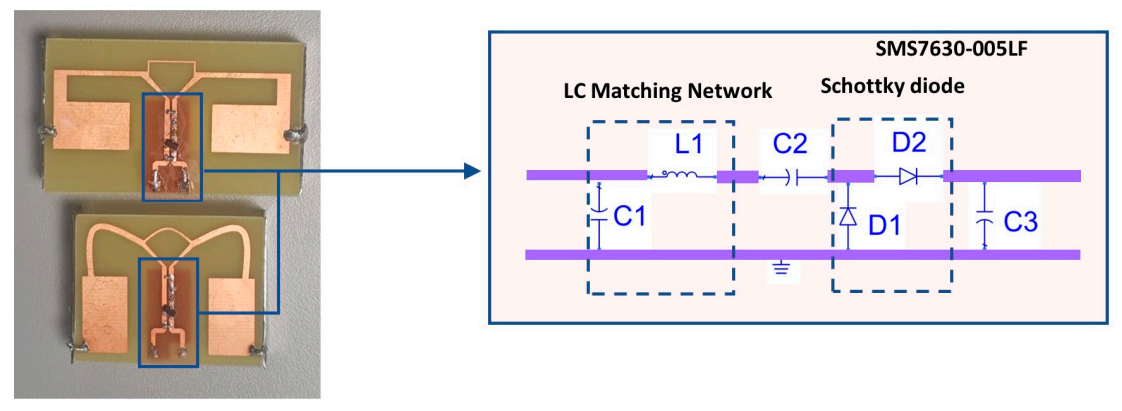

Figure 12. Manufactured rectenna with the rectifier schematic.

The conversion efficiency as a function of the power density is presented in Figure 13. It is obtained by computing the formula given in Equation (2), where:

- $\quad P_{D C}$ is the harvested DC power obtained across the load;

- $\quad G t$ and Gr are the transmitting antenna gain and the receiver antenna gain;

- $\quad \lambda$ is the wavelength at the operating frequency;

- $\quad S$ is the electromagnetic (EM) power density and $P_{t}$ is the $R F$ power from the source;

- $\quad d$ is the distance between the transmitting and receiving antennas.

The variation by decade shows a difference between R1 and R2 of $13.67 \%, 6.01 \%$ and $1.48 \%$. The difference can be explained by the non-linearity of the used Schottky diode. By reducing the planar antenna size of $30 \%$, we reduce the antenna gain of $0.44 \mathrm{dBi}$ and then the RF-DC conversion efficiency of $13 \%$ with a power density of $3.1 \mu \mathrm{W} / \mathrm{cm}^{2}$ at $868 \mathrm{MHz}$. The second rectenna R2 will be preferred in cases where the power density is very low (e.g., $31 \mathrm{nW} / \mathrm{cm}^{2}$ ). For our application, in the aim of supplying the power management unit, which requires a DC voltage of $600 \mathrm{mV}$ at least, $\mathrm{R} 1$ was chosen.

$$
\eta=100 \cdot \frac{P_{D C}}{P_{R F}}=100 \cdot \frac{4 \cdot \pi \cdot P_{d c}}{S \cdot G_{r} \cdot \lambda^{2}} \text { with } S=\frac{E^{2}}{120 \cdot \pi}=\frac{30 \cdot P_{t} \cdot G_{t}}{d^{2} \cdot 120 \cdot \pi}
$$

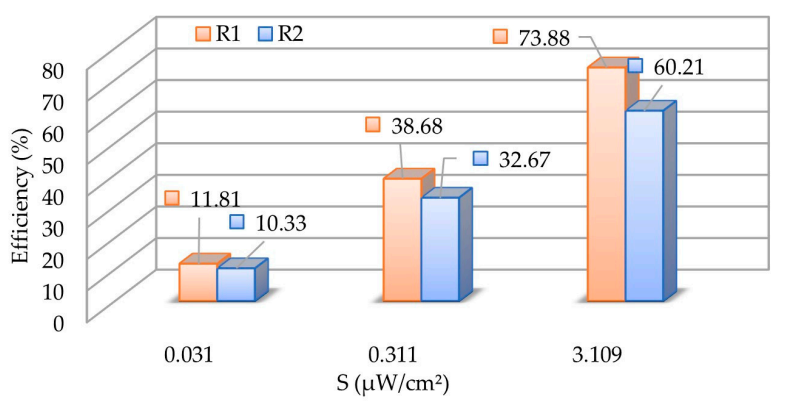

Figure 13. RF-DC conversion efficiency for the rectennas at $868 \mathrm{MHz}$ for various decade power densities.

In the last set of tests, underrun in our laboratory, an innovative Bluetooth Low Energy (BLE) battery-free wireless sensor network (composed of battery-free sensing nodes and a communicating node [26]) was operated in a harsh environment (Figure 14). Once embedded, the main objectives were to periodically monitor the physical data (e.g., temperature and humidity) of the concrete and broadcast them (by BLE) to the communicating node. 


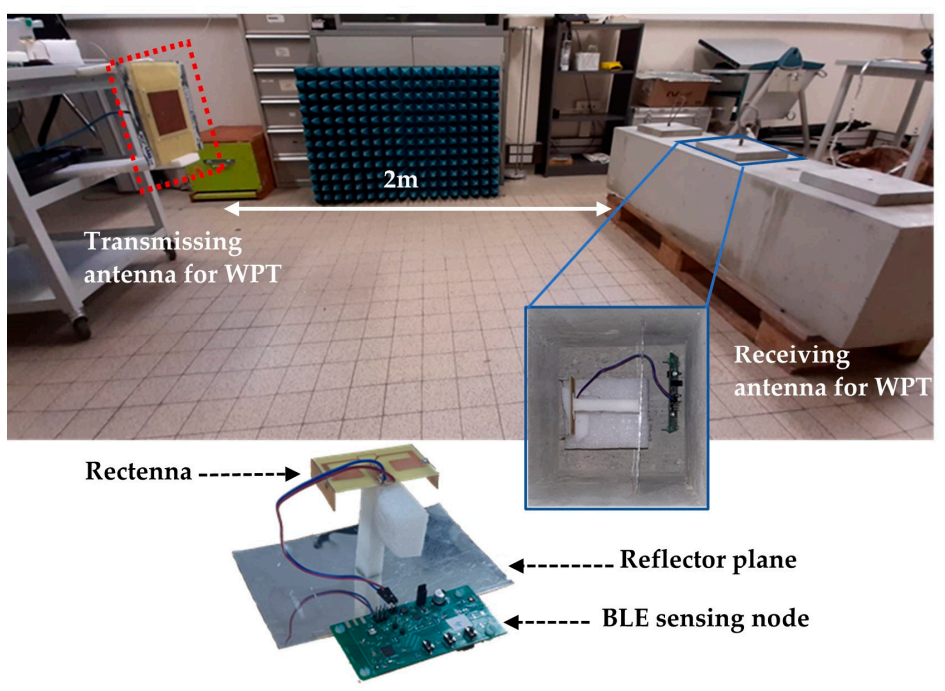

Figure 14. Photograph of the experimental setup for the sensing node embedded and powered by using WPT system in the concrete structure.

The sensing node in Figure 15 is composed of a rectenna (including the compact 3D antenna), an ultra-low-power BLE System on Chip (SoC) (NXP QN9080) [27], a power management unit microcontroller (Texas Instruments bq25570) [28], a capacitor of $100 \mu \mathrm{F}$ acting as an energy storage element (Panasonic EEEFK0J101P) [29] and low-power temperature and humidity digital sensors (Texas Instruments HDC2080) [30]. The capacitor was chosen after evaluating the power needed by the PMU $(870 \mu \mathrm{J})$ to startup from deep-sleep mode. Through a far field WPT system, the illuminating power over a distance of two meters can be harvested by the rectenna and allow powering the sensing node. Initially empty, the capacitor is charging through the PMU on deep-sleep mode up to $1.5 \mathrm{~V}$ and switches on fast charging until the stored voltage reaches $5.3 \mathrm{~V}$. Once it has enough energy stored by the capacitor, it discharges and allows powering the active component on the board (sensors and BLE chip) for a measurement and data transmission.

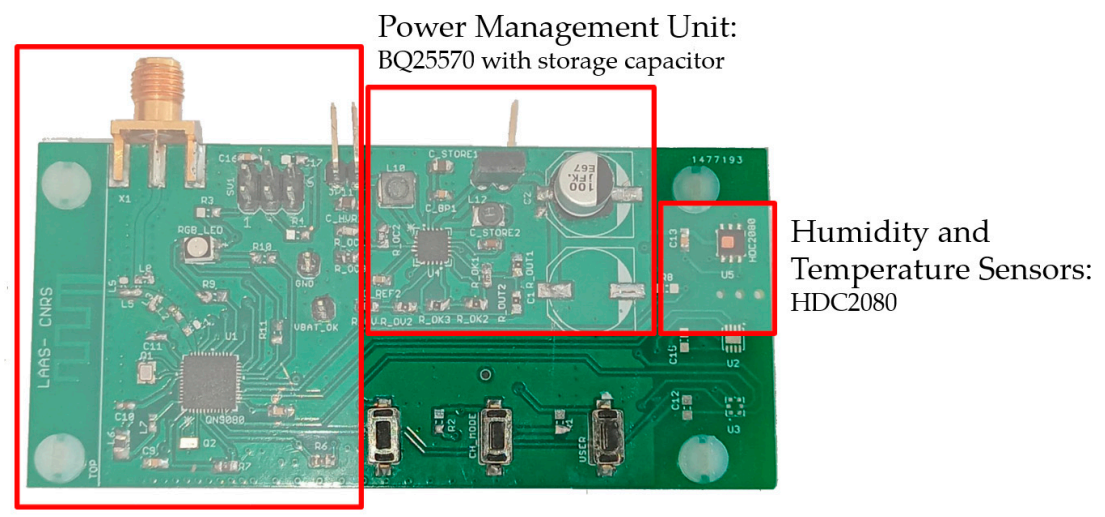

BLE Transceiver : PIFA

Antenna and QN9080 Chip with programmable pins

Figure 15. Developed sensing node for BLE communication.

Preliminary tests, with an EIRP power of $+33 \mathrm{dBm}$, allow a periodicity of charging, measuring and wireless communication equal to at most $190 \mathrm{~s}$, representing the first charge duration (cold start + fast charging + data measurement and transmission). 


\section{Conclusions}

An electrically small antenna operating in the ISM $868 \mathrm{MHz}$ frequency band and dedicated to wireless power transmission applications is proposed in this paper. Its design is based on a folded dipole antenna with a shorting line to form a T-match antenna. A $3 \mathrm{D}$ configuration allows the exploitation of the Z-plane in the final implementation. Thus, the connection of two metallic arms was operated by the planar antenna to downshift the operating frequency from $1.09 \mathrm{GHz}$ to $868 \mathrm{MHz}$. The design was modified to apply a spline shape to the planar antenna arms in order to reduce the overall dimensions (in the horizontal plane) from $56 \mathrm{~mm} \times 32 \mathrm{~mm}$ to $40 \mathrm{~mm} \times 30 \mathrm{~mm}$.

For the characterization, three feeding methods were used to provide accurate experimental results. In this application, the U.FL connector can be used for measurement but may have limitations at higher frequencies. The experimental results confirm that the proposed 3D antenna exhibits a gain of $+1.54 \mathrm{dBi}$ and $+1.1 \mathrm{dBi}$ at the operating frequency, respectively, for $\mathrm{AC}$ and $\mathrm{A} 2$. As shown in Table 1, a tradeoff between the compactness, the maximal gain and the bandwidth should be performed before the design. Our solution is also the most compact and has a maximum gain higher than $+1 \mathrm{dBi}$ at the price of a reduced bandwidth. The combination of these antennas and an optimized rectifier performs a high efficiency of $73.88 \%$ and $60.31 \%$, respectively, for R1 and R2 with an illuminating power density of $3.1 \mu \mathrm{W} / \mathrm{cm}^{2}$. Future works with a WPT system associated with a battery-free wireless sensor network using BLE are in progress.

Author Contributions: Conceptualization, A.S. and A.T.; methodology, A.S.; software, A.S.; validation, A.S. and G.L.; investigation, A.T.; writing-original draft preparation, A.S, A.T., G.L. and D.D.; writing - review and editing, A.S., A.T., G.L. and D.D.; supervision, D.D.; project administration, A.T. and D.D.; funding acquisition, A.T. and D.D. All authors have read and agreed to the published version of the manuscript.

Funding: Region OCCITANIE, France in the frame of the OPTENLOC project, supported this research. The system tests were performed in the frame of the ANR McBIM project.

Institutional Review Board Statement: Not applicable.

Informed Consent Statement: Not applicable.

Conflicts of Interest: The authors declare no conflict of interest.

\section{References}

1. Carminati, M.; Sinha, G.R.; Mohdiwale, S.; Ullo, S.L. Miniaturized Pervasive Sensors for Indoor Health Monitoring in Smart Cities. Smart Cities 2021, 4, 146-155. [CrossRef]

2. Donchev, E.; Pang, J.; Gammon, P.; Centeno, A.; Xie, F.; Petrov, P.; Alford, N. The rectenna device: From theory to practice (a review). MRS Energy Sustain. 2014, 1, E1. [CrossRef]

3. Lin, L.C.; Chiu, C.; Gong, J. A Wearable Rectenna to Harvest Low-Power RF Energy for Wireless Healthcare Applications. In Proceedings of the 11th International Congress on Image and Signal Processing, BioMedical Engineering and Informatics (CISP-BMEI), Beijing, China, 30 August-15 September 2018; pp. 1-5.

4. Takacs, A.; Okba, A.; Aubert, H. Compact Planar Integrated Rectenna for Batteryless IoT Applications. In Proceedings of the 48th European Microwave Conference (EuMC), Madrid, Spain, 23-27 September 2018; pp. 777-780.

5. Shafique, K.; Khawaja, B.A.; Khurram, M.D.; Sibtain, S.M.; Siddiqui, Y.; Mustaquin, M.; Chattha, T.H.; Yang, X. Energy Harvesting Using a Low-Cost Rectenna for Internet of Things (IoT) Applications. IEEE Access 2018, 6, 30932-30941. [CrossRef]

6. Pizzotti, M.; Perilli, L.; Del Prete, M.; Fabbri, D.; Canegallo, R.; Dini, M.; Masotti, D.; Costanzo, A.; Franchi Scarselli, E.; Romani, A. A Long-Distance RF-Powered Sensor Node with Adaptive Power Management for IoT Applications. Sensors 2017, 17, 1732.

7. Okba, A.; Takacs, A.; Aubert, H. Compact Flat Dipole Rectenna for IoT Applications. Prog. Electromagn. Res. C 2018, 87, 39-49. [CrossRef]

8. Rokunuzzaman, M.; Islam, M.T.; Rowe, W.S.T.; Kibria, S.; Singh, M.J.; Misran, N. Design of a Miniaturized Meandered Line Antenna for UHF RFID Tags. PLoS ONE 2016, 11, e0161293. [CrossRef] [PubMed]

9. Gianvittorio, J.P.; Rahmat-Samii, Y. Fractal antennas: A novel antenna miniaturization technique, and applications. IEEE Antennas Propag. Mag. 2002, 44, 20-36. [CrossRef]

10. Das, S.; Sawyer, D.J.; Diamanti, N.; Annan, A.P.; Iyer, A.K. A strongly miniaturized and inherently matched folded dipole antenna for narrowband applications. IEEE Antennas Propag. Mag. 2019, 68, 3377-3386. [CrossRef] 
11. Babar, A.A.; Virtanen, J.; Bhagavati, V.A.; Ukkonen, L.; Elsherbeni, A.Z.; Kallio, P.; Sydänheimo, L. Inkjet-printable UHF RFID tag antenna on a flexible ceramic-polymer composite substrate. In Proceedings of the IEEE MTT-S International Microwave Symposium Digest (MTT '12), Montreal, QC, Canada, 17-22 June 2012; pp. 1-3.

12. Li, K.; Zhu, C.; Li, L.; Cai, Y.M.; Liang, C.H. Design of electrically small metamaterial antenna with ELC and EBG loading. IEEE Antenn. Wirel. Pract. Lett. 2013, 12, 678-681. [CrossRef]

13. Balanis, C.A. Frequency Independent Antennas, Antenna Miniaturization, and Fractal Antennas. In Antenna Theory: Analysis and Design, 3rd ed.; John Wiley: Hoboken, NJ, USA, 2005; pp. 637-640.

14. Wheeler, H.A. Fundamental Limitations of Small Antennas. Proc. IRE 1947, 35, 1479-1484. [CrossRef]

15. Marrocco, G. The art of UHF RFID antenna design: Impedance-matching and size-reduction techniques. IEEE Antennas Propag. Mag. 2008, 50, 66-79. [CrossRef]

16. Niotaki, K.; Kim, S.; Jeong, S.; Collado, A.; Georgiadis, A.; Tentzeris, M.M. A Compact Dual-Band Rectenna Using Slot-Loaded Dual Band Folded Dipole Antenna. IEEE Antennas Wirel. Propag. Lett. 2013, 12, 1634-1637. [CrossRef]

17. Balanis, C.A. Broadband Dipoles and Matching Techniques. In Antenna Theory: Analysis and Design, 3rd ed.; John Wiley: Hoboken, NJ, USA, 2005; pp. 538-541.

18. Ting, J.; Oloumi, D.; Rambabu, K. A miniaturized broadband bow-tie antenna with improved cross-polarization performance. Int. J. Electron. Commun. 2017, 78, 173-180. [CrossRef]

19. Durgun, A.C.; Balanis, C.A.; Birtcher, C.R.; Allee, D.R. Design, Simulation, Fabrication and Testing of Flexible Bow-Tie Antennas. IEEE Trans. Antennas Propag. 2011, 59, 4425-4435. [CrossRef]

20. U.FL Series Connector HIROSE Electric Group. Available online: https://www.hirose.com/product/series/U.FL?lang=en (accessed on 5 December 2019).

21. Zahid, S.; Quddious, A.; Tahir, F.A.; Vryonides, P.; Antoniades, M.; Nikolaou, S. Dual-Band Compact Antenna for UHF and ISM Systems. In Proceedings of the 13th European Conference on Antennas and Propagation (EuCAP), Krakow, Poland, 31 March-5 April 2019; pp. 1-5.

22. Trinh, L.H.; Nguyen, T.Q.K.; Phan, D.D.; Tran, V.Q.; Bui, V.X.; Truong, N.V.; Ferrero, F. Miniature antenna for IoT devices using LoRa technology. In Proceedings of the International Conference on Advanced Technologies for Communications (ATC), Quy Nhon, Vietnam, 18-20 October 2017; pp. 170-173.

23. Asadallah, F.A.; Eid, A.; Shehadeh, G.; Costantine, J.; Tawk, Y.; Tentzeris, M.M. Digital Reconfiguration of a Single Arm Three-Dimensional Bowtie Antenna. IEEE Trans. Antennas Propag. 2020. [CrossRef]

24. Sidibe, A.; Loubet, G.; Takacs, A.; Dragomirescu, D. Energy Harvesting for Battery-Free Wireless Sensors Network Embedded in a Reinforced Concrete Beam. In Proceedings of the 50th European Microwave Conference (EuMC), Utrecht, The Netherlands, 12-14 January 2021; pp. 702-705.

25. Sidibe, A.; Takacs, A. Compact 3D Rectenna for Low-Power Wireless Transmission. In Proceedings of the XXXIV URSI General Assembly and Scientific Symposium (URSI GASS), Rome, Italy, 28 August-4 September 2021.

26. Loubet, G.; Takacs, A.; Gardner, E.; De Luca, A.; Udrea, F.; Dragomirescu, D. LoRaWAN Battery-Free Wireless Sensors Network Designed for Structural Health Monitoring in the Construction Domain. Sensors 2019, 19, 1510. [CrossRef] [PubMed]

27. NXP Semiconductors. QN908x Ultra-Low-Power BLE SoC. Available online: https://www.nxp.com/docs/en/nxp/data-sheets/ QN908x.pdf (accessed on 12 January 2021).

28. Texas Instruments. bq25570 Ultra Low-Power Harvester power Management IC with boost charger and Nanopower Buck Converter. Available online: http:/ / www.ti.com/lit/ds/symlink/bq25570.pdf (accessed on 12 January 2021).

29. Panasonic. EEEFK0J101P Aluminum Electrolytic Capacitors. Available online: https://industrial.panasonic.com/cdbs/wwwdata/pdf/RDE0000/ABA0000C1181.pdf (accessed on 12 January 2021).

30. Texas Instruments. Ultra-Low-Power, Digital Humidity Sensor with Temperature Sensor HDC2080. Available online: https: //www.ti.com/lit/ds/symlink/hdc2080.pdf (accessed on 12 January 2021). 